\title{
Marathon Running During Chemotherapy: Where Are the Limits?
}

\author{
Fernando C. Dimeo \\ Section Sports Medicine, Charité University Hospital Berlin, Germany
}

In the past, physicians usually advised cancer patients to rest and avoid physical effort. These recommendations were empirical: since the disease and its treatment can generate functional changes resulting in impaired physical performance, exercise in this group of patients may cause fatigue, breathlessness, and tachycardia. Therefore, avoiding physical activity results in less discomfort. However, it is now well established that excessive rest and lack of physical activity may result in severe deconditioning and, thus, reduce the functional status and quality of life of cancer patients. The world class performances of athletes like the Tour de France winner Lance Armstrong and the World and Olympic champion Ludmila Endquist, who have been treated for cancer, focused attention on the effects of training on the physical performance of cancer patients. Meanwhile there is a large body of experience about the effects, possibilities and contraindications of exercise in cancer patients. In their article in this issue of OnKologie, Bernhörster et al. [1] report on a patient who starts marathon training while undergoing chemotherapy for Hodgkin's disease. Few days after successfully finishing the race without health issues, she received the last chemotherapy application.

\section{References}

1 Bernhörster M, Rosenhagen A, Vogt L, Thiel C Jäger E, Banzer W: Marathon run under chemotherapy - is it possible? Onkologie 2011;34: DOI: $10.1159 / 000327804$.
This case report is in line with the current opinion, namely to allow and promote exercise even during cancer treatment. A regular exercise program can help patients to reduce the negative effects of cancer and its treatment, improve their stamina and mood, and increase their quality of life. However, what applies for training does not always apply for competition: a marathon race is an extreme event that has been associated with musculoskeletal injuries, heat stroke or hypothermia, thrombosis, dilutional hyponatremia, transient ventricular dysfunction and elevated troponin concentration, and increased risk of coronary artery calcification. Therefore, participation at a marathon race requires a long and careful preparation. What is possible is not necessarily recommendable. However, we congratulate both the patient and the medical team for their courage and their willingness to reach for new frontiers. This successful story suggests that we should reevaluate our ideas about the ability of cancer patients to perform physical exercise.

\section{Disclosure Statement}

The author does not have any potential conflicts of interests concerning this article.
PD Dr. med. Fernando C. Dimeo

Abteilung Sportmedizin

Charité Universitätsmedizin Berlin

Hindenburgdamm 30, 12200 Berlin, Germany

Tel. +49 30 8445-2098, Fax -4767

Fernando.dimeo@charite.de 